\title{
Lambl's excrescences and a review of therapeutic strategies
}

\author{
Benedict Osorio*1, Linle Hou ${ }^{1}$, Jack Xu ${ }^{1}$, Eric Pagan ${ }^{1}$, Michael Piscopiello ${ }^{2}$ \\ ${ }^{1}$ Department of Internal Medicine, Rutgers Robert Wood Johnson Medical School, New Jersey, United States \\ ${ }^{2}$ Department of Cardiology, Penn Medicine Princeton Health, New Jersey, United States
}

Received: May 15, 2018

Accepted: June 14, 2018

Online Published: June 25, 2018

DOI: $10.5430 /$ crim.v5n3p13

URL: https://doi.org/10.5430/crim.v5n3p13

\begin{abstract}
Background: Lambl's excrescences (LEx) are thin, filiform structures that arise on the lines of closure of heart valves. Although rare, we have come across various case reports in the literature describing thromboembolic events associated with LEx. We report the case of a 63-year-old female who presented with TIA-like symptoms and was found to have a LEx on the aortic side of native aortic valve. We conducted a comprehensive literature review with emphasis on different therapeutic strategies utilized to provide insight for future encounters.

Case presentation: A 63-year-old female with a past medical history significant for hypertension and hyperlipidemia presented to the emergency room with symptoms of dysarthria and unsteady gait. While in the hospital, the patient returned to her baseline gait and speech without intervention. Work-up for including computed tomography of the head, magnetic resonance imaging, and carotid doppler, as well as prolonged telemetry monitoring was negative. A transthoracic echocardiogram showed a $0.81 \mathrm{~cm}$ linear echodensity attached to the aortic side of the aortic valve, highly suggestive of LEx that was later confirmed on transesophageal echocardiogram. Patient was placed on clopidogrel alone for antiplatelet therapy due to an aspirin allergy and she was subsequently discharged home.

Discussion: No standard management for LEx currently exists. We aim to add to the evidence of effective management and explore the literature of patients who have experienced TIA/CVA symptoms secondary to LEx.
\end{abstract}

Key Words: Lambl's excrescence, Cryptogenic stroke, Thromboembolism

\section{BACKGROUND}

Lambl's excrescences (LEx), first described by Bohemian physician Vilém Dušan Lambl in 1856, are thin, mobile, filiform structures that arise on the lines of heart valve closures. $^{[1-3]}$ They are thin (up to $1.5 \mathrm{~mm}$ in width) and elongated, varying from $5 \mathrm{~mm}$ to $10 \mathrm{~mm} \cdot{ }^{[4,5]}$ Some excrescences, known as giant LEx's, have been noted to be up to $2.5 \mathrm{~cm}$ in length. ${ }^{[6]}$ There are two types of excrescences with different age population, lamellar and filiform, that were found by Hurle et al. Lamellar excrescences occurred more often in those younger than 30 years old, while filiform excrescences most often occur more frequently in persons older than 40 years old. ${ }^{[7]}$ These structures are thought to be secondary to intimal damage - the continual striking of the valve causes small areas of damage to the endothelium - allowing fibrin to cover the damaged area. This fibrin structure becomes partially uplifted from the valve surface. A layer of intimal cells than covers the fibrous tissue, making the excrescence. ${ }^{[8,9]}$ Histopathologically, these structures are a central core of elastic connective tissue, covered by a single

*Correspondence: Benedict Osorio; Email: bo117@rwjms.rutgers.edu; Address: Department of Internal Medicine, Rutgers Robert Wood Johnson Medical School, New Jersey, United States.

Published by Sciedu Press 
layer of endothelial cells. ${ }^{[2]}$ The differential diagnosis of a mobile structure off of a heart valve includes but not limited to, LEx, papillary fibroelastoma, cardiac myxoma, infective endocarditis, thrombus, and dissection of the aorta. ${ }^{[10]}$

LEx have been described on both native and prosthetic valves, but they are most commonly found on the atrial side of the mitral valve and the ventricular side of the aortic valve. ${ }^{[11]}$ In a study by Roldan et al., they performed echocardiography on 227 patients, and found 95 of who had LEx, and 21 of those patients had them on multiple valves. 69 patients found excrescences on the mitral valve, 41 on the aortic valve, 6 on the tricuspid valve, and 1 on the pulmonic valve. ${ }^{[4]}$ It has been reported that LEx can be found on $70 \%-80 \%$ of adult heart valves, and there is a similar prevalence of LEx in both healthy subjects and patients with or without suspected cardio-embolic disease, regardless of age or gender. ${ }^{[4,12]}$ Although rare, various case reports exist in literature describing thromboembolic events associated with LEx. These include transient ischemic attack (TIA), ischemic stroke, myocardial infarction, and embolization to peripheral arteries. ${ }^{[6,13-15]}$ While no standard management for LEx currently exists, various case reports describe the management of patients who have stroke-like symptoms using anticoagulation, antiplatelet, surgical excision, and conservative management. ${ }^{[3,8,16,17]}$ In this report, we present a case of TIA likely secondary to embolism of LEx on the aortic side of the native aortic valve. We also conducted a comprehensive literature review with an emphasis on different therapeutic strategies utilized to provide insight for future encounters.

\section{Case Presentation}

The patient is a 63-year-old female with a past medical history significant for hypertension and hyperlipidemia who presented to the emergency room with symptoms of dysarthria and unsteady gait. Her symptoms started three days prior to presentation, associated with recurrent episodes of slurred speech and word finding difficulty. She did not have any focal, facial, or limb weakness. However, she suffered multiple episodes of mechanical fall due to unsteady gait. On presentation, vitals and laboratory studies were normal and physical exam was otherwise unremarkable, including a normal neurologic examination. Computed Tomography (CT) of the head and Magnetic Resonance Imaging (MRI) of the brain did not show any acute intracranial pathology. Doppler of the carotids did not demonstrate any cerebrovascular insufficiency in extracranial carotid artery system. Electrocardiogram (ECG) and continuous telemetry monitoring did not demonstrate any cardiac arrhythmia. Transthoracic echocardiogram showed borderline low ejection fraction and mild aortic valve leaflet thickening with a linear echodensity attached to the aortic side of aortic valve that was highly suggestive of LEx. It was later confirmed on transesophageal echocardiogram (see Figure 1). No histopathology was obtained for this patient, as she was treated medically. Patient was subsequently placed on clopidogrel alone for antiplatelet therapy due to her prior aspirin allergy and the patient was subsequently discharged home with plan for close outpatient follow-up.

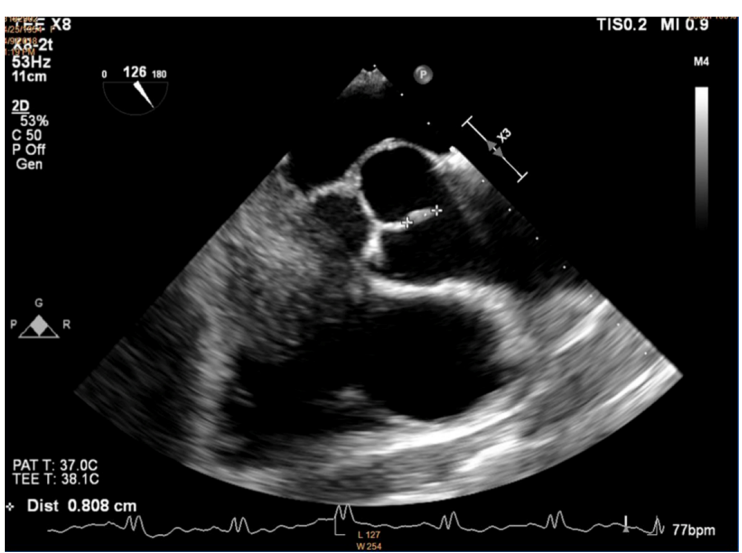

Figure 1. Transesophageal echocardiogram demonstrating $0.81 \mathrm{~cm}$ echodense structure on the aortic side of native aortic valve suggestive of LEx

\section{Discussion}

No standard of management for LEx currently exists. A comprehensive literature review with an emphasis on the different therapeutic strategies was done, summarized below (see Table 1). Exclusion criteria included any studies where a LEx was an incidental finding and when patients were already on anticoagulation or antiplatelet therapy for other reasons. As noted previously, LEx are more commonly found on the atrial side of the mitral valve and the ventricular side of the aortic valve. However, most symptomatic patients were found to have LEx on the aortic valve, ${ }^{[3,6,11,13-16,18-34]}$ as our patient had.

Previous case reports have suggested a variety of treatment modalities, including anticoagulation, antiplatelet therapy, surgical excision, and conservative management. ${ }^{[15,24,27,34-37]}$ Medical management within itself varied greatly, ranging from aspirin alone, dual antiplatelet therapy, novel oral anticoagulants, to full anticoagulation therapy with warfarin. ${ }^{[18,24,27,34,36]}$ Roldan et al. performed a study that suggests LEx may not be a source of cardioembolic strokes, and it may be reasonable to not treat them at all. ${ }^{[4]}$ While there is no consensus on a preferred treatment modality, our literature review revealed that in five of the six studies where the patient presented with a TIA, the patients were treated 
with a combination of antiplatelet therapy with different patient with TIA/CVA symptoms secondary to LEx given the agents, and only one patient was treated with surgical exci- bleeding risk on antiplatelet/anticoagulation therapy. Those sion. ${ }^{[13,16,34-36,39]}$ In a patient whose medical compliance patients also experienced positive outcomes, similar to those may be an issue, surgical excision may be a better option for a managed conservatively. ${ }^{[17,19,21,23]}$

Table 1. Case reports involving symptomatic Lambl's excrescences

\begin{tabular}{|c|c|c|c|c|c|}
\hline Reference & $\begin{array}{l}\text { Patient } \\
\text { Demographics }\end{array}$ & Location of LE & Presentation & Management & Follow-up outcome \\
\hline Kalavakunta $^{[3]}$ & 59 y/o M & Aortic valve & CVA & Warfarin & $\begin{array}{l}\text { No further neurological deficits that } \\
\text { hospital course }\end{array}$ \\
\hline Aggarwal $^{[6]}$ & 66 y/o F & Aortic valve & CVA & $\begin{array}{l}\text { Anticoagulation; Surgical } \\
\text { excision }\end{array}$ & Not reported \\
\hline $\operatorname{Voros}^{[8]}$ & $72 \mathrm{y} / \mathrm{o} \mathrm{M}$ & Pulmonic valve & CVA & Conservative management & Not reported \\
\hline Kamran $^{[11]}$ & 74 y/o F & Aortic valve & CVA & Anticoagulation & Not reported \\
\hline Siles ${ }^{[13]}$ & $42 \mathrm{y} / \mathrm{o} \mathrm{M}$ & Aortic valve & TIA & ASA $200 \mathrm{mg}$ & $\begin{array}{l}\text { No neurological event at } 1 \text { year } \\
\text { follow-up }\end{array}$ \\
\hline Mito $^{[14]}$ & 50 y/o F & Aortic valve & MI & Not reported & Not reported \\
\hline Fitzgerald ${ }^{[15]}$ & $70 \mathrm{y} / \mathrm{o} \mathrm{M}$ & Unknown & $\begin{array}{l}\text { Sudden onset of pain in the } \\
\text { left leg - embolus to } \\
\text { popliteal artery }\end{array}$ & Echocardiogram; no intervention & $\begin{array}{l}\text { Periodic echocardiograms for } \\
18 \text { months - no other events noted }\end{array}$ \\
\hline $\mathrm{Chu}^{[16]}$ & $51 \mathrm{y} / \mathrm{o} \mathrm{F}$ & Aortic valve & TIA & ASA 81 mg, clopidogrel 75 mg & $\begin{array}{l}\text { No neuro events at } 6 \text { months } \\
\text { follow-up }\end{array}$ \\
\hline Al-ansari ${ }^{[17]}$ & 33 y/o M & Mitral valve & CVA & Surgical excision & Not reported \\
\hline Davogustto $^{[18]}$ & 68 y/o F & Aortic valve & CVA & ASA $81 \mathrm{mg}$ & $\begin{array}{l}\text { No recurrence of symptoms at } 2 \text { years } \\
\text { follow-up }\end{array}$ \\
\hline Aziz $^{[19]}$ & $61 \mathrm{y} / \mathrm{o} \mathrm{F}$ & Aortic valve & AMS & Surgical excision & $\begin{array}{l}10 \text { days after discharge }- \text { no neuro } \\
\text { events noted }\end{array}$ \\
\hline Quinson ${ }^{[20]}$ & 64 y/o F & Aortic valve & Angina & Surgical excision & $\begin{array}{l}\text { No neuro events at } 3 \text { months } \\
\text { follow-up }\end{array}$ \\
\hline Berent $^{[21]}$ & $44 \mathrm{y} / \mathrm{o} \mathrm{F}$ & Aortic valve & Weakness and fatigue & Surgical excision & Not reported \\
\hline Wolf $^{[22]}$ & $47 \mathrm{y} / \mathrm{o} \mathrm{F}$ & Aortic valve & CVA & ASA $100 \mathrm{mg}$ & No neuro events at 6-month follow-up \\
\hline \multirow{2}{*}{$\operatorname{Liu}^{[23]}$} & 53 y/o M & Aortic valve & CVA & ASA $100 \mathrm{mg}$ & Symptom-free at 9 months \\
\hline & 30 y/o M & Aortic valve & CVA & Surgical excision & Symptom-free at 7-month follow-up \\
\hline $\mathrm{Wu}^{[24]}$ & 66 y/o F & Aortic valve & CVA & Warfarin & No neuro event at 6-month follow-up \\
\hline Yacoub $^{[25]}$ & 59 y/o M & Aortic valve & CVA & ASA and Lipitor & Not reported \\
\hline Raju $^{[26]}$ & $44 \mathrm{y} / \mathrm{o} \mathrm{M}$ & Aortic valve & CVA & $\begin{array}{l}\text { Surgical excision; discharged on } \\
\text { antiplatelet therapy }\end{array}$ & Not reported \\
\hline Meireles ${ }^{[27]}$ & $56 \mathrm{y} / \mathrm{o} \mathrm{F}$ & Aortic valve & CVA & Rivaroxaban 20 mg daily & $\begin{array}{l}\text { Not reported; neurologic improvement } \\
\text { noted }\end{array}$ \\
\hline Rhee $^{[28]}$ & $21 \mathrm{y} / \mathrm{o} \mathrm{M}$ & Aortic valve & CVA & ASA 100 mg daily & No neuro event after 3 years follow-up \\
\hline Pizzuti $^{[29]}$ & 59 y/o M & Aortic valve & MI & Surgical excision & Not reported \\
\hline Dangas $^{[30]}$ & 75 y/o F & Aortic valve & Unstable Angina & Surgical excision & Not reported \\
\hline Vlacancich $^{[31]}$ & 39 y/o F & Aortic valve & CVA & Dual antiplatelet therapy & Not reported \\
\hline Kariyanna ${ }^{[32]}$ & 62 y/o F & Aortic valve & CVA & ASA and high-dose statin & Not reported \\
\hline Manolakis ${ }^{[33]}$ & $47 \mathrm{y} / \mathrm{o} \mathrm{F}$ & Aortic valve & CVA & $\begin{array}{l}\text { Warfarin (not adherent) } \\
\text { Surgical excision }\end{array}$ & $\begin{array}{l}\text { Experienced another stroke, secondary } \\
\text { to cocaine use }\end{array}$ \\
\hline \multirow{2}{*}{$\mathrm{Jo}^{[34]}$} & 54 y/o M & Aortic valve & TIA & Clopidogrel and ASA & No neuro event after 2 years follow-up \\
\hline & $78 \mathrm{y} / \mathrm{o} \mathrm{M}$ & Aortic valve & CVA & Dabigatran & Not reported \\
\hline Villella $^{[35]}$ & 63 y/o M & Mitral valve & TIA & Antiplatelet therapy & $\begin{array}{l}\text { Still having symptoms } 2 \text { months later, } \\
\text { but less frequent }\end{array}$ \\
\hline $\operatorname{Ker}^{[36]}$ & 32 y/o M & Mitral valve & TIA & ASA 100 mg, clopidogrel 75 mg & No neuro event after 3 years follow-up \\
\hline Fumero $^{[37]}$ & $30 \mathrm{y} / \mathrm{o} \mathrm{M}$ & Mitral valve & CVA & Surgical excision & No neuro event after 1 year follow-up \\
\hline $\begin{array}{l}\text { Nighoghossian } \\
\text { [38] }\end{array}$ & 31 y/o M & Mitral valves & Recurrent CVA & $\begin{array}{l}\text { Acenocoumarol; Surgical } \\
\text { excision }\end{array}$ & Not reported \\
\hline Bruinsma $^{[39]}$ & 34 y/o M & Mitral valve & TIA & Surgical excision & Not reported \\
\hline
\end{tabular}


Chu et al. suggested LEx should be included in the differential diagnosis of cryptogenic stroke, and if found on TEE, should be treated with dual antiplatelet therapy. ${ }^{[16]}$ Ker et al and Rhee et al. are two studies with the longest follow-up of three years. Both studies had young male patients; Ker's patient was treated with dual antiplatelet therapy, while Rhee's patient was treated with aspirin alone. ${ }^{[28,36]}$ The CHANCE trial suggests dual antiplatelet therapy with clopidogrel and aspirin is superior to aspirin alone for reducing the risk of stroke in patients who had experienced a TIA or minor stroke without increasing the risk of hemorrhage. ${ }^{[40]}$

Given the clinical significance, we believe that more studies regarding the management of LEx should be done.

\section{Conclusion}

As Chu et al. suggested, LEx should be considered in the differential diagnosis of cryptogenic stroke. Although rare and under represented, it is imperative to have a consensual standard management plan for patients suffering form cardioembolic disease secondary to LEx. Using the case of our patient as an example, we aim to add to the evidence of effective management of patients who have experienced TIA/CVA symptoms secondary to LEx by successful treatment with antiplatelet therapy.

\section{CONSENT}

Consent for publication was obtained from the patient.

\section{CONFlicts OF INTEREST Disclosure}

The authors declare no conflicts of interest.

\section{REFERENCES}

[1] Lambl VD. Papillare exkreszenzen an der semilunar-klappe der aorta. Wien Med Wochenschr. 1856; 6: 244-7.

[2] Jaffe W, Figueredo VM. An example of Lambl's excrescences by transesophageal echocardiogram: a commonly misinterpreted lesion. Echocardiography. 2007; 24(10): 1086-1089. PMid:18001363. https://doi.org/10.1111/j.1540-8175.2007.00533.x

[3] Kalavakunta JK, Peddi P, Bantu V, et al. Lambl's excrescences: a rare cause of stroke. J Heart Valve Dis. 2010; 19(5): 669-670. PMid:21053748.

[4] Roldan CA, Shively BK, Crawford MH. Valve excrescences: prevalence, evolution and risk for cardioembolism. J Am Coll Cardiol 1997; 30(5): 1308-1314. https://doi.org/10.1016/S0735-1 $097(97) 00315-\mathrm{X}$

[5] Freedberg RS, Goodkin GM, Perez JL, et al. Valve strands are strongly associated with systemic embolization: a transesophageal echocardiographic study. J Am Coll Cardiol. 1995 Dec; 26(7): 170912. https://doi.org/10.1016/0735-1097(95) 00394-0

[6] Aggarwal A, Leavitt BJ. Images in clinical medicine. Giant Lambl's excrescences. N Engl J Med. 2003; 349(25): e24. PMid:14681522. https://doi.org/10.1056/ENEJMicm010900

[7] Hurle JM, Garcia-Martinez V, Sanchez-Quintana D. Morphologic characteristics and structure of surface excrescences (Lambl's excrescences) in the normal aortic valve. Am J Cardiol. 1986 Dec 1; 58(13): 1223-7. https: //doi .org/10.1016/0002-9149(86) 90386-3

[8] Voros S, Nanda NC, Thakur AC, et al. Lambl's Excrescences (Valvular Strands). Echocardiography. 1999; 16(4): 399-414. PMid:11175169. https://doi.org/10.1111/j.1540-8175.19 99.tb00833.x

[9] Magarey FR. On the mode of formation of Lambl's excrescences and their relation to chronic thickening of the mitral valve. J Pathol Bacteriol. 1949 Apr; 61(2): 203-8.

[10] Nakahira J, Sawai T, Katsumata T, et al. Lambl's excrescence on aortic valve detected by transesophageal echocardiography. Anesth Analg. 2008 Jun; 106(6): 1639-40. PMid:18499592. https://doi org/10.1213/01.ane.0000313440.93243.6b
[11] Kamran H, et al. Lambl's excrescences: A case report and review of the literature. Clinical Case Reports and Reviews. 2016; 2(7): 486488. PMid:27917298. https://doi.org/10.15761/CCRR . 1000 254

[12] McAllister HA, Hall RJ, Cooley DA, et al. Tumors of the heart and pericardium. Current Problems in Cardiology. 1999; 24(2): 59-116. https://doi.org/10.1016/S0146-2806(99)80001-2

[13] Siles Rubio JR, Ruiz de Castroviejo del Campo J, Tirado Miranda R, et al. Transient ischemic attack due to Lambl's excrescence. Report of a case and review of the literature. An Med Interna. 2006; 23(4): 181-183.

[14] Mito M, Kiyuna M, Toda T, et al. A rare case report of incarceration of Lambl's excrescence of aortic valve resulting in myocardial infarction. Rinsho Byori. 2012; 60(8): 758-761. PMid:23198535.

[15] Fitzgerald D, Gaffney P, Dervan P, et al. Giant Lambl's excrescence presenting as a peripheral embolus. Chest. 1982; 81(4): 516-517. PMid:7067520. https://doi.org/10.1378/chest.81.4.516

[16] Chu A, Aung TT, Sahalon H, et al. Lambl's Excrescence Associated with Cryptogenic Stroke: A Case Report and Literature Review. The American Journal of Case Reports. 2015; 16: 876-881. PMid:26655393. https://doi .org/10.12659/AJCR. 895456

[17] Al-Ansari S, Hindori V, Riezebos RK, et al. Multiple Lambl's excrescences with subvalvular extension, a rare cause of cryptogenic stroke: treated by port-access cardiac surgery. BMJ Case Reports. 2013; 2013: bcr2013201161

[18] Davogustto G, Fernando RR, Loghin C. Lambl's Excrescence, Migrainous Headaches, and "Tiger Stripes": Puzzling Findings in One Patient. Texas Heart Institute Journal. 2015; 42(1): 70-72. PMid:25873805. https ://doi.org/10.14503/THIJ-13-3808

[19] Aziz F, Baciewicz FA, Jr. Lambl's excrescences: review and recommendations. Tex Heart Inst J. 2007; 34(3): 366-368. PMid:17948090.

[20] Quinson P, de Gevigney G, Boucher F, et al. Fibrous aortic valve tumor (Lambl's excrescence) trapped in the right coronary artery. Apropos of a case. Arch Mal Coeur Vaiss. 1996; 89(11): 1419-1423. PMid:9092401. 
[21] Berent R, Hartl P, Rossoll M, et al. Lambl's excrescence as tumorous heart valve mass. Dtsch Med Wochenschr. 1998; 123(14): 423-426. PMid:9581169. https ://doi.org/10.1055/s-2007-1023981

[22] Wolf RC, Spiess J, Huber R. Lambl's excrescence and cerebral ischemic insult. Nervenarzt. 2006; 77(12): 14921494. PMid:17102989. https://doi.org/10.1007/s00115-0 06-2198-4

[23] Liu RZ, Yu SY, Li Y. Migraine-like headache and ischemic strokes in two patients with Lambl's excrescences. Chin Med J (Engl). 2012; 125(18): 3346-3348.

[24] Wu TY, Gerber IL, Roxburgh RH. Thrombo-embolic cerebral infarction secondary to giant Lambl's excrescence. J Clin Neurosci. 2013; 20(11): 1632-1634. PMid:23669170. https://doi.org/10.101 $6 /$ j. jocn. 2012.08 .015

[25] Yacoub HA, Walsh AL, Pineda CC. Cardioembolic stroke secondary to Lambl's excrescence on the aortic valve: a case report. Journal of Vascular and Interventional Neurology. 2014; 7(3): 23-25. PMid:25298855.

[26] Raju V, et al. Double Giant Lambl's Excrescence of aortic valve causing posterior circulation stroke. 2011.

[27] Meireles VG, et al. Lambl's Excrescences in a Woman with Recurrent Changes of Consciousness. Available from: https://Portalre vistas.ucb.br/Index.php/Rmsbr/Article/View/6943, 23 Mar. 2017

[28] Rhee HY, Choi HY, Kim SB, et al. Acute Ischemic Stroke in a Patient with a Native Valvular Strand. Case Reports in Neurology. 2010; 2(2): 91-95. PMid:20671864. https://doi.org/10.1159/000317117

[29] Pizzuti A, Parisi F, Mosso L, et al. Acute Myocardial Infarction in a Patient with Two-Vessel Occlusion and a Large Lambl's Excrescence. Case Reports in Cardiology. 2016: 6. https://doi.org/10.115 $5 / 2016 / 8370212$

[30] Dangas G, Dailey-Sterling FG, Sharma SK, et al. Non-Q-wave infarction and ostial left coronary obstruction due to giant Lambl's excrescences of the aortic valve. Circulation. 1999; 99(14): 1919-
1921. PMid:10199892. https://doi.org/10.1161/01.CIR.99. 14.1919

[31] Vlacancich RH, Case BC. Lambl's Excrescences - A Forgotten Cause of Cryptogenic Strokes? Open Journal of Clinical \& Medical Case Reports. 2017; 3(22)

[32] Kariyanna PT, et al. Recurrent Cardio-embolic Cerebrovascular Accidents due to Lambl's Excrescences? American Journal of Medical Case Reports. 2016; 4(3): 93-96.

[33] Manolakis C, et al. Lambl Excrescences in a Woman With Recurrent Strokes. Lambl Excrescences in a Woman With Recurrent Strokes I Consultant. 2011; 360.

[34] Jo KD, Kim JE, Jang W, et al. Lambl's excrescences associated with cyptogenic stroke. Journal of the Neurological Sciences. 2017; 381: 525. https://doi.org/10.1016/j.jns.2017.08.3688

[35] Villella E, Aulivola B. Lambl's Excrescence: Innocent Bystander or Culprit Lesion in Cerebrovascular Embolism? Journal of Vascular Surgery. 2015; 62(3): 835. https://doi.org/10.1016/j.jvs. 2015.06 .192

[36] Ker J. The serpentine mitral valve and cerebral embolism. Cardiovascular Ultrasound. 2011; 9: 7. PMid:21352582. https ://doi .org/ 10. 1186/1476-7120-9-7

[37] Fumero A, Villalba L, Kemeny JL, et al. Coexisting chordal papillary fibroelastoma and leaflet Lambl's tumour of the mitral valve. Interact Cardiovasc Thorac Surg. 2003; 2(3): 382-384. https : //doi.org/10.1016/S1569-9293(03)00081-1

[38] Nighoghossian N, Trouillas P, Perinetti M, et al. Lambl's excrescence: an uncommon cause of cerebral embolism. Rev Neurol (Paris). 1995; 151(10): 583-585.

[39] Bruinsma GJBB, Leicher FG. Lambl's excrescences of the mitral valve. Netherlands Heart Journal. 2002; 10(1): 23-24 PMid:25696029.

[40] Wang YJ, Wang YL, Zhao XQ, et al. Clopidogrel with aspirin in acute minor stroke or transient ischemic attack. N Engl J Med. 2013; 369(1): 11-19. PMid:23803136. https://doi.org/10.1056/NE JMoa1215340 